\title{
Impact Mitigation of COVID-19 Pandemic on Pediatric HIV Care
}

\author{
Mukesh Vir Singh ${ }^{1} \cdot$ Shahid Akhtar Siddiqui ${ }^{1}$ (iD \\ Received: 12 March 2021 / Accepted: 12 April 2021 / Published online: 28 April 2021 \\ (C) Dr. K C Chaudhuri Foundation 2021
}

To the Editor: Severe acute respiratory syndrome coronavirus 2 (SARS CoV-2) pandemic has disrupted normal lives. Its emergence has created another health burden for children and adolescents living with human immunodeficiency virus/ acquired immunodeficiency syndrome (HIV/AIDS) (CLHIV). Recently, the CDC has highlighted that people living with HIV (PLWH) are at increased risk for severe physical health illness from coronavirus disease 2019 (COVID-19) [1] Due to disruptions caused by COVID-19, delivery of effective healthcare and access to HIV treatment was anticipated to be adversely affected. We, herein share experience at our pediatric antiretroviral therapy (ART) center to explore the potential impact of COVID-19 on HIV care.

To contain spread of SARS-CoV-2 India imposed lockdown on March 24, 2020. National AIDS Control Organization (NACO) guidelines were received regarding administering local level mechanisms for decentralization of services. There were 323 active cases of CLHIV under care before the lockdown and 10 clients $(3.1 \%)$ were nonadherent, while after the lockdown, 46 clients $(14.2 \%)$ were nonadherent in April, 2020 and another 27 clients (8.3\%) missed drugs in May, 2020 ( $p$ value $<0.0001$ for MarchApril and $p$ value $=0.0044$ for March-May). Thus, despite decentralization of services, HIV care in CLHIV was significantly affected by the lockdown with a significant improvement from April to May 2020 ( $p$ value $=0.0177$ ).

Syndemic interactions between COVID-19 and HIV may interfere with HIV services. Effect of global pandemic ultimately falls among vulnerable groups of low- to middleincome countries [2,3]. CLHIV need regular access to healthcare to maintain viral suppression providing optimal

Shahid Akhtar Siddiqui

sha.akht@yahoo.com

1 Department of Pediatrics, S.N. Children Hospital, M.L.N. Medical College, Prayagraj, Uttar Pradesh, India clinical benefits and reducing HIV transmission [4]. Strategies to tackle COVID-19 pandemic (staying home, avoiding group gatherings/functions, social distancing, and hand washing) pose unique challenges to HIV care. So there was a need of adapting mode of service delivery. Decentralization was successful to some extent at our center. Innovative replication and adaptation of this approach will be helpful in optimal HIV care delivery services across different settings.

Acknowledgments The authors are thankful to the Principal and Director of the institute Dr. (Prof.) S. P. Singh, all faculties, residents, and hospital support staff of the institute.

\section{Declarations}

Ethical Approval Ethical approval was taken from the Institutional Ethics Committee, M.L.N Medical College and associated hospitals, Prayagraj (Ethics Committee registration number ECR/922/inst/UP/ 2017 issued under rule 122DD/ of the Drugs \& Cosmetics Rule, 1945) with permission number 002 dated June 20, 2020.

Conflict of Interest None.

\section{References}

1. https://www.cdc.gov/coronavirus/2019-ncov/specific-groups/hiv. html. Accessed 1 January 2021.

2. Earnshaw VA, Smith LR, Chaudoir SR, Amico KR, Copenhaver MM. HIV stigma mechanisms and well-being among PLWH: a test of the HIV stigma framework. AIDS Behav. 2013;17(5):1785-95.

3. Gilbert M, Pullano G, Pinotti F, et al. Preparedness and vulnerability of African countries against importations of COVID-19: a modelling study. Lancet. 2020;395:871-7.

4. Saag MS, Benson CA, Gandhi RT, et al. Antiretroviral drugs for treatment and prevention of HIV infection in adults: 2018 recommendations of the international antiviral society-USA panel. JAMA. 2018;320(4):379-96.

Publisher's Note Springer Nature remains neutral with regard to jurisdictional claims in published maps and institutional affiliations. 